\title{
Feline Hypersomatotropism, an Important Cause for the Failure of Insulin Therapy
}

\author{
Madalina ROSCA, Mihai MUSTEATA, Carmen SOLCAN, Gabriela Dumitrita STANCIU*, Gheorghe SOLCAN \\ Faculty of Veterinary Medicine, University of Agricultural Science and Veterinary Medicine "Ion Ionescu \\ de la Brad", Iasi, Romania \\ * corresponding author: gdstanciu@yahoo.com
}

Bulletin UASVM Veterinary Medicine 71(2) / 2014,

Print ISSN 1843-5270; Electronic ISSN 1843-5378

DOI:10.15835/buasvmcn-vm: 10288

\begin{abstract}
Hypersomathotropism is an important feline endocrinopathy, induced by a pituitary growth hormone secreting adenoma. Up until present, most of the diagnosed acromegalic cats were diagnosed previously with insulin dependent diabetes mellitus. Hypersomathotropism needs imperative exclusion when dealing with poor blood glucose control and insulin resistance. The present paper describes hypersomathotropism diagnosis protocol in two insulin resistant diabetic felines.

Two diabetic domestic short hair cats presenting marked insulin resistance and poor blood glucose control were evaluated. Diagnosis protocol included anamnesis, physical evaluation and general and specific biochemistry analysis. Diagnosis confirmation was obtained on contrast enhanced intracranial MRI and morphopathological examination.

Both cases displayed marked insulin resistance with $1.5 \mathrm{IU} / \mathrm{kg} /$ administration in the male cat 10.5 IU/administration) and $2.4 \mathrm{I} . \mathrm{U} . / \mathrm{kg} /$ administration in the female cat (12 I.U./administration). On physical examination have been observed a slight inferior prognathia on the female cat, clubbed paws on the male cat, broad facial features and obesity (female: $5 \mathrm{~kg}$; male: $7 \mathrm{~kg}$ ). Repeated blood glucose curves confirmed persistent hyperglycaemia $>450 \mathrm{mg} / \mathrm{dl}(61-124 \mathrm{mg} / \mathrm{dl})$ with different doses of insulin. Specific biochemistry revealed an increased concentration of insulin like growth factor-1 determination $>1000 \mathrm{ng} / \mathrm{ml}(208-443 \mathrm{ng} / \mathrm{ml})$, above the cut-off for hypersomathotropism diagnosis. Contrast enhanced MRI revealed an enlarged pituitary gland confirming hypersomathotropism. Haematoxylin eosin examination of the pituitary tissue revealed acidophilic cells consistent with growth hormone producing cells.

Systemic manifestations are masked by diabetes mellitus clinical signs leading to a high error degree in diagnostic establishment and administration of highly dangerous doses of insulin. With accurate diagnosis, case management and specific treatment can be applied accordingly and in the favor of patient quality of life.
\end{abstract}

Keywords: acromegaly, insulin-like-growth factor-1, insulin resistance, pituitary adenoma, feline growth hormone.

\section{INTRODUCTION}

Diabetes mellitus in cats in almost $85 \%$ of cases resembles human type II diabetes. Hyperglycemia is usually the result of a low secretion or inadequate response to endogenous insulin. Insulin treatment in "normal" diabetic felines requires $<1 \mathrm{IU} / \mathrm{kg} / \mathrm{administration}$, offering an adequate blood glucose control. If the initial cause of insulin deficiency is treated and exogenous insulin administration manages to hold a tight blood glucose control, hyperglycemia might resolve and thus so insulin requirement could seize. Requirement of doses of insulin higher than $1.5 \mathrm{IU} / \mathrm{kg} /$ administration or frequent dose fluctuations, should drive clinicians to evaluate for insulin resistance (IR) and pathologies which could cause an inadequate response to treatment. Insulin resistance is defined as reduced sensitivity to insulin, with little or no response in blood glucose lowering effect. Inadequate response to insulin is caused by low availability of insulin receptors (pre-receptor defect), incapacity of 
insulin to bind to receptors (receptor defect), and/or incapacity of signal transduction after the binding of insulin to the receptor (postreceptor defect) (Scott-Moncrieff, 2010). The most important conditions demonstrated to cause insulin resistance are obesity, exogenous progestagens and glucocorticoid, pancreatitis, bacterial infections, renal and heart disease and neoplasia (Scott-Moncrieff, 2010). Underlying endocrinopathies such as hypersomathotropism, hyperadrenocorticism and hyperthyroidism evolve with high concentrations of insulin antagonist hormones which in turn will lead to an overproduction of insulin by the pancreas, to the exhaustion and shutdown of $\beta$-cells (Behrend and Kemppainen, 1997; Middleton and Watson, 1985; Peterson, 2007; Zini et al., 2010). Hypersomatotropism in cats, as in humans, is caused by a functional somatotrophic adenoma developed on growth hormone $(\mathrm{GH})$ producing cells of the pars distalis in the anterior pituitary gland (Niessen, 2010; Rijnberk et al., 2003; Starkey et al., 2004). Insulin resistance and diabetes mellitus induced by GH and IGF-1 is the result of down regulation of insulin receptors and post-receptor defects in glucose transport (Niessen et al., 2007). In a healthy organism, GH secretion is stimulated by the Growth Hormone Releasing Hormone secreted in the hypothalamus and inhibited by somatostatin. In patients with tumours of GH producing cells, hormone secretion becomes autonomous and does not respond to the negative feedback.

Acromegalic cats tend to be middle aged, with a median of 10 years, no apparent breed disposition and are 90\% males (Niessen, 2010; Scott-Moncrieff, 2010). Hypersomathotropism clinical signs and are rarely observed by owners and clinicians, as they are usually discrete and develop over months or even years. Predominant clinical signs are of DM and most cases present poor blood glucose control and the requirement of high doses of insulin.

\section{MATERIALS AND METHODS}

Two diabetic domestic short hair cats, a 14-year-old spayed female cat and a 7 year old unneutered male, were documented with marked insulin resistance and poor blood glucose control after being diagnosed with diabetes mellitus. Although insulin treatment was initiated longer than six weeks before revaluation, both cases still presented persistent polyuria $(>50 \mathrm{ml} / \mathrm{kg} /$ day), polydipsia ( $>150 \mathrm{ml} / \mathrm{kg} /$ day), ravenous appetite and weight gain. Insulin dose has been increased gradually over six weeks in order to obtain an adequate blood glucose control. Both cases reached a high dangerous insulin dose of $2.4 \mathrm{IU} / \mathrm{kg} / \mathrm{administration}$ in the female cat $(12$ IU/administration) and $1.5 \mathrm{IU} / \mathrm{kg} / \mathrm{administration}$ in the male cat (10.5 IU/administration). Hypersomathotropism suspicion was based on the marked insulin resistance, weight gain and obesity (female: $5 \mathrm{~kg}$; male: $7 \mathrm{~kg}$ ) in spite of poor blood glucose control.

Patients were submitted to a clinical, cardiac and neurological revaluation. General biochemistry targeted: blood glucose level, liver enzymes, cholesterolemia, azotaemia, phosphataemia and urine biochemistry. Diagnosis confirmation was based on IGF-1, a specific parameter for hyperadrenocorticism, and intracranial contrast enhanced MRI. Contrast enhanced intracranial MRI was performed under general anaesthesia, with a 1.5 Toshiba Vantage Titan, with a slice thickness of $3 \mathrm{~mm}$. Pre and post contrast images were acquired in $\mathrm{T} 1$ and $\mathrm{T} 2$ in dorsal, sagittal and transverse planes. Contrast enhancement images were obtained by intravenous administration of gadobenate dimeglumine $0.1 \mathrm{mmol} / \mathrm{kg}$.

\section{RESULTS AND DISCUSSION}

The prevalence of feline acromegaly is not yet accurately known. However it could be the decreased awareness on the pathology and predominant diabetes mellitus clinical contributing to the decreased prevalence of acromegaly. Diabetes mellitus is in a lot of cases the first pathology to be discovered and only later on, after insulin treatment failure, leading to hypersomathotropism suspicion (Feldman and Nelson, 2000; Meij et al., 2010). Acromegalic cats tend to be middle aged, with a median of 10 years, no apparent breed disposition and are $90 \%$ males (Niessen, 2010; Scott-Moncrieff, 2010). Physical examination often reveals: inferior prognatia, widened interdental spaces, respiratory stridor in $53 \%$ of cases (Niessen, 2010), clubbed paws and weight gain (Niessen, 2010; Scott-Moncrieff, 2010). Physical examination often reveals: inferior prognatia, widened interdental spaces, respiratory stridor in $53 \%$ of cases (Niessen, 
2010), clubbed paws and weight gain (Niessen, 2010; Scott-Moncrieff, 2010). Physical evaluation in the present cases was characteristic for hypersomathotropism. A slight inferior prognathia (Fig. 1) on the female cat, clubbed paws (Fig. 2) on the male cat and broad facial features on both cats have been observed, all features representative for acromegaly (Niessen et al., 2007). Overgrowth of soft, skeletal and cartilage tissue and organomegaly are caused by the anabolic effect of not only GH, but also insulin like growth factor - 1 (IGF-1), which is produced mainly by the liver, under the direct influence of high concentrations of GH (Niessen, 2010; Rijnberk et al., 2003; Starkey et al., 2004). Acromegaly is characterized by slow, progressive, somatic disfigurement, involving mainly the face, extremities and internal organs (Chanson et al., 2009). GH and IGF-1 are involved not only in the proliferation of normal cells, but also neoplasic cells (Marek et al., 2001). Elevated concentrations of GH and IGF-1 lead to increased cell turnover and high risk of malignant transformation (Juul, 2003). Different forms of cancer as lymphosarcoma, adenocarcinoma (Norman and Mooney, 2000) or osteosarcoma (Abraham et al., 2002) have been observed in acromegalic cats. On cardiac auscultation, normal frequency, without murmurs and synchronic pulse was present on both femoral arteries were registered. Cats did not display any signs of astazia, ataxia, nistagmus, seizures or circling. The only neurological signs observed on the female case were bilateral mydriasis, diminished pupillary light reflex and aggressive behaviour.

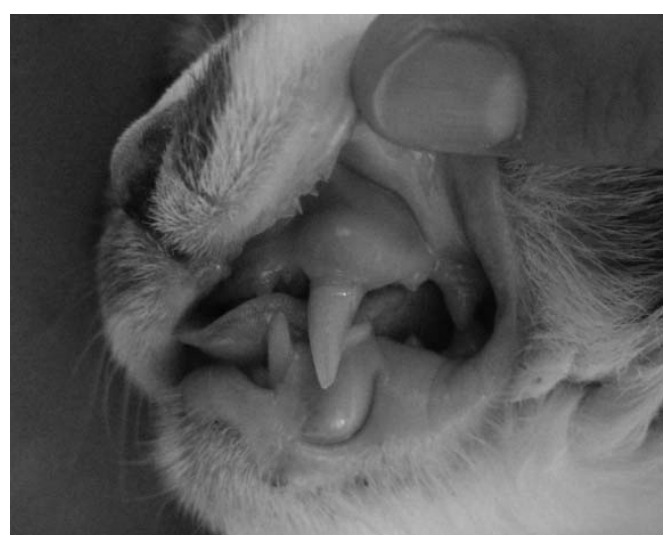

Fig. 1. Slight inferior prognatia and widened interdental spaces in the female cat;
Blood results revealed hyperglycaemia, increased alkaline phosphatasis, hypercholesterolemia, hyperkalaemia, moderately increased hepatic transaminases and hyperproteinemia. Urinalyses revealed marked glycosuria $(>1081.08$ $\mathrm{mg} / \mathrm{dl})$ with a normal specific gravity (1.020 1.040) and the urine culture was negative. Specific biochemistry revealed an increased concentration of insulin like growth factor-1 determination above the $1000 \mathrm{ng} / \mathrm{ml}(208-443 \mathrm{ng} / \mathrm{ml})$ cut-off for hypersomathotropism diagnosis.

Most acromegalic cats reported in literature up until now, were also were previously diagnosed with insulin dependent diabetes mellitus, which sets a differentiation from human hypersomathotropism. Cats displaying IR are usually presented with persistent characteristic signs of diabetes mellitus, such as polyuria, polydipsia and polyphagia and weight gain. Increasing weight despite poor blood glucose control should be one of the factors indicating an underlying IR inducing endocrinopathy. A high percentage of diabetic hypersomathotropic cats displayed poorly controlled blood glucose and required highly dangerous doses of insulin (Dunning et al., 2009; Feldman and Nelson, 2000; Niessen, 2010; Slingerland et al., 2008). Severe episodes of hypoglycemia are at risk, as GH has a pulsatile episodic secretion, leaving fluctuating gaps in the IR, when insulin could have a normal hypoglycemic effect. Insulin resistance can be confirmed if a high level of fructosamine $>500 \mathrm{mg} / \mathrm{dl}$ and persistent hyperglycemia on blood glucose curve are detected (Scott-Moncrieff, 2010).

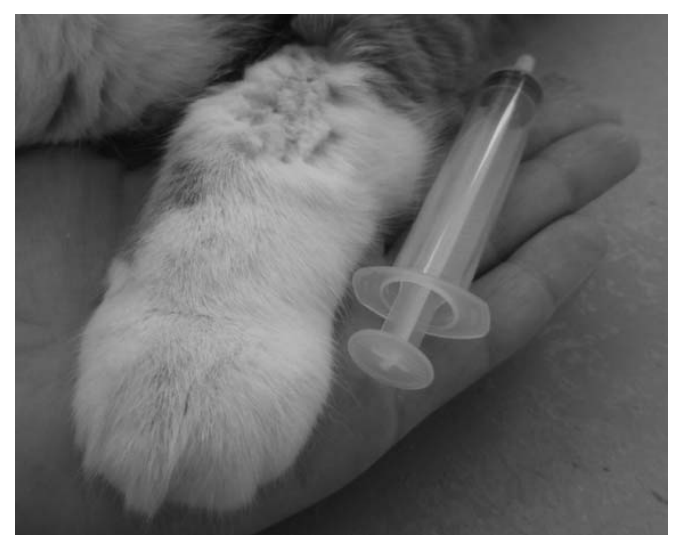

Fig. 2. Clubbed paws observed in the acromegalic male cat; 
Confirmation of acromegaly includes levels of IGF-1, specific feline GH determinations and intracranial imaging by contrast enhanced MRI (Niessen, 2010). Even with a reduced availability specific feline $\mathrm{GH}$ can be determined in cats (Niessen et al., 2007). However GH single determination cannot be reliable for diagnosis, due to its episodic pulsatile secretion, short halflife and influence of numerous variables on serum levels. A higher reliability is owned by IGF-1, as it is secreted in a non-pulsatile fashion (Niessen et al., 2007; Scott-Moncrieff, 2010; Slingerland et al., 2008), reflects the average 24 hour GH activity (Starkey et al., 2004) and has a parallel increase with GH (Chanson et al., 2009). IGF-1 has a highly conserved structure across different species and does not require specific feline tests, making radio immune and ELISA assays designed for diagnosis of acromegaly in humans, adequate for cats (Berg et al., 2007; Feldman and Nelson, 2000; Niessen, 2010; Rosca et al., 2014; Starkey et al., 2004).

Finally, if GH and/or IGF-1 register elevated levels, diagnosis is confirmed by intracranial imaging of the pituitary by CT or MRI (Niessen et al., 2007).

Contrast enhanced MRI revealed an enlarged pituitary gland confirming hypersomathotropism diagnosis (Fig. 3). The pituitary gland was described as a nonhomogeneous mass in T1 images, with multiple well demarked lacunar areas of hypointense content and hyperintense rims. On the T2 examination same mixed predominant hypointense signal and hyperintense rims were observed, with one large hypointense lacuna and ventral hyperintense foci. Sagittal images revealed a nonhomogeneous highly intense rostral rim (Fig. 3). Pituitary measurement results (Wallack et al., 2003) indicated a height of $0.8 \mathrm{~cm}$, width of 0.7 $\mathrm{cm}$, length of $0.7 \mathrm{~cm}$ and a volume of $0.2051 \mathrm{~cm}^{3}$.

Tab. 1. Blood general and specific biochemistry for hypersomathotropism diagnosis

\begin{tabular}{|c|c|c|c|}
\hline Analyte & Female cat & Male cat & Reference range \\
\hline Glucose & 412 & 480 & $61-124 \mathrm{mg} / \mathrm{dl}$ \\
\hline Cholesterol & 176 & 299 & 71-161 mg/dl \\
\hline Alkaline Phosph. & 37 & 92 & $12-65 \mathrm{UI} / \mathrm{L}$ \\
\hline Urea nitrogen & 57 & 21 & 15-31 mg/dl \\
\hline Phosphate & 7.9 & 7.3 & $4-7.3 \mathrm{mg} / \mathrm{dl}$ \\
\hline ALAT & 31.4 & 46 & 8.3-53 UI/L \\
\hline ASAT & 46 & 68 & 9.2-40 UI/L \\
\hline Potassium & 6 & 5.2 & 3.8-5.3 mEq/l \\
\hline IGF-1 & 1600 & 1000 & $208-443 \mathrm{ng} / \mathrm{ml}$ \\
\hline
\end{tabular}

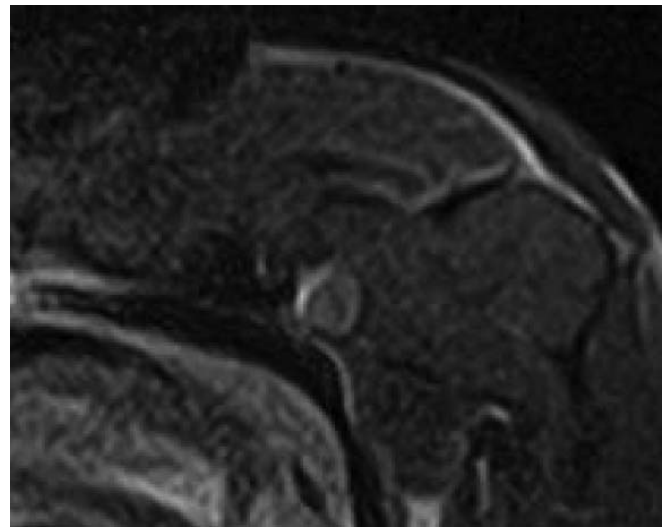

Fig. 3. MRI Postcontrast T1 sagittal section nonhomogeneous highly intense rostral rim of the pituitary gland;

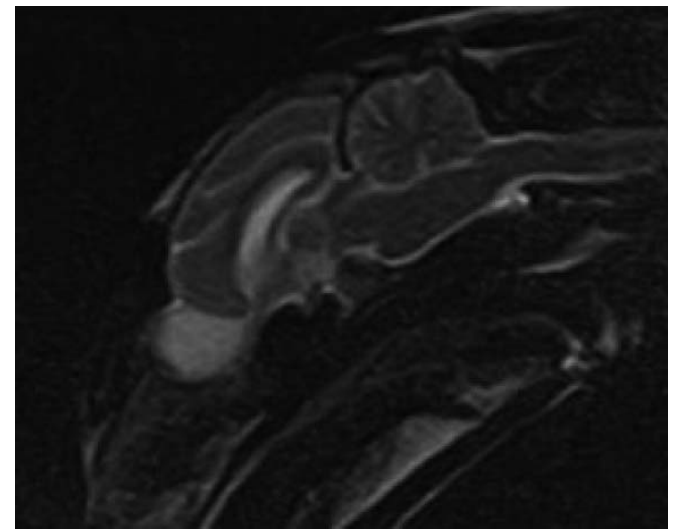

Fig. 4. MRI Precontrast T2 sagittal section Hyperintense aspect of the olfactory bulbs; 
An eventual suprasellar extension of the pituitary could not be demonstrated but the mass effect that caused the deviation of third ventricle and lateral ventricle asymmetry may be suggestive for a hypothalamic extension. Olfactory bulbs revealed bilateral liquid filled cavitary areas, with grey aspect in T1 and FLAIR and white in T2 images, characteristic for cerebral spinal fluid. This was suggestive for an increased volume of ventricular cavities in the olfactory bulbs (Fig. 4), later confirmed on post-mortem examination. In this case the MR images revealed a pituitary gland with a volume of $0.2051 \mathrm{~cm} 3$, being considerably higher than in normal cats. The pituitary gland of adult cats with no pituitary diseases was proved to have a mean length of $0.54 \mathrm{~cm}( \pm 0.06 \mathrm{~cm})$, mean width of $0.50 \mathrm{~cm}( \pm 0.08 \mathrm{~cm})$, mean height 0.34 $\mathrm{cm}( \pm 0.05 \mathrm{~cm})$ and a mean volume of $0.05 \mathrm{~cm} 3( \pm$ $0.05 \mathrm{~cm} 3$ ) with no significant correlation between the volume and the age or weight of the cat (Wallack et al., 2003). The pituitary gland was described as a nonhomogeneous mass with multiple well demarked lacunar areas of hypointense content and hyperintense rims. Sagittal images revealed nonhomogeneous highly intense rostral rims, which was previously reported in other studies and was suspected to be a consequence of fatty infiltration caused by chronic inflammation or compression (Posch et al., 2011; Wallack et al., 2003).

Beside the findings that accord with previous studies described in literature, in this case MR images indicated increased volume of olfactory bulbs cavities, which was also confirmed on the post-mortem examination and is the first report of this kind. No obstruction or compression was revealed between lateral ventricles and olfactory bulbs cavities, but this must be evaluated with reserve considering the small diameter of binding channels.

After confirming the diagnosis of acromegaly, the owner of the female had decided for euthanasia and agreed for necropsy. Tissue samples from the pituitary gland, liver, adrenal glands, kidney and the left submandibular gland that appeared enlarged were collected for histology. Haematoxylin eosin staining of the pituitary tissue revealed acidophilic cells, consistent with GH secreting cells adenomas (Fig. 5) with no evidence of basophilic cells characteristic to ACTH secreting cells (Meij et al., 2004). Markedly vacuolated islet cells in the pancreas, periglomerular fibrosis, degenerative and regenerative epithelial cells in the kidney and mild to moderate cholangiohepatitis in the liver tissues were also observed. Results for IGF-1 level showed a concentration of $1600 \mathrm{ng} / \mathrm{dl}$ (208- 443 $\mathrm{ng} / \mathrm{ml}$ ) which was suggestive for acromegaly as it exceeded $1000 \mathrm{ng} / \mathrm{ml}$.

Advanced researches have been made in the past years on feline acromegaly. Early and accurate diagnosis could improve the outcome, not only for the main endocrinopathy but also for its secondary associated pathologies. Better quality of life, increased life expectancy and overall a better prognosis could be obtained. Treatment options for acromegaly are aimed at lowering of GH and

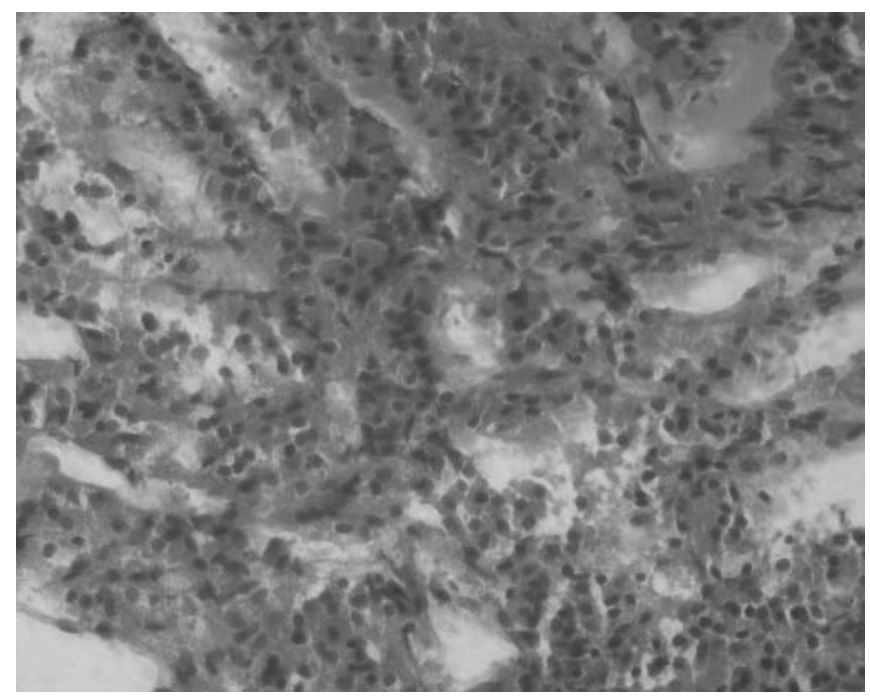

Fig. 5. Pituitary gland hematoxylin eosin staining - acidophilic cells 
IGF-1, reducing tumour size and include medical treatment, radiotherapy protocols, surgical hypophysectomy, and cryohypophysectomy (Blois and Holmberg, 2008; Brearley et al., 2006; KaserHotz et al., 2002; Meij et al., 2010). Although radiotherapy and surgical approach are considered curative for hypersomathotropism, these methods are readily chosen as they are invasive, require repeated sedation and imply high costs. Post surgical treatment requires lifelong hormonal replacement. Research are being made on the medical treatment of acromegaly, an important compound being pasireotide (SOM 23), a drug used for human Cushing's disease treatment. In a study performed in 2013 by Niessen et al. results revel that pasireotide is able to rapidly decrease GH and IGF-1 concentrations in feline acromegaly. A clinical trial with long-acting release form of pasireotide is still in progress in order to establish long-term effects and potential for IR and DM remission acromegalic cats (Niessen et al., 2013). Acromegalic cats have a life expectancy that varies between 4 to 42 months. Cause of death is in most cases consequence of severe congestive heart failure, renal failure or progressive neurological signs caused by the expanding pituitary tumours (Abraham et al., 2002; Feldman and Nelson, 2000).

\section{CONCLUSION}

Insulin resistance in cats can be induced by a variousnumberofconditionsand endocrinopathies. Error rate in the establishment of diagnosis is high and is dependable on the clinicians experience and knowledge of all pathologies which could lead to a poor blood glucose control. Insulin resistance recognition and further evaluation for underlying pathologies is essential for a favourable disease outcome and a good quality of life for the patient. Hypersomathotropism has an insidious evolution, with discrete clinical signs, often marked by diabetes mellitus concurrent evolution. Systemic manifestations are dominated by diabetes mellitus clinical signs leading to a high error degree to, a delayed accurate diagnosis and administration of highly dangerous amounts of insulin. Consequently, so is the specific treatment for hypersomatotropism. Early diagnosis could offer along with the most suitable therapeutic measures a better prognostic. Insulin administration should not exceed certain dose unless all underlying pathologies have been excluded. Also cats recei- ving high doses of insulin should be under a constant care and monitoring in order to prevent life threatening hypoglycaemic episodes.

Acknowledgments. The first author acknowledges the support of the project "Improvement and Development of Human Resource for Research and Innovation through Doctoral School" POSDRU -CPP107-DMI1/5/S/77222.

\section{REFERENCES}

1. Abraham LA, Helmond SE, Mitten RW, Charles JA, Holloway SA (2002). Treatment of an acromegalic cat with the dopamine agonist L-deprenyl. Aust Vet J 80: 479-483.

2. Behrend EN, Kemppainen RJ (1997). Glucocorticoid therapy. Pharmacology, indications, and complications. Vet Clin North Am Small Anim Pract 27: 187-213.

3. Berg RI, Nelson RW, Feldman EC, Kass PH, Pollard R, Refsal KR (2007). Serum insulin-like growth factor-I concentration in cats with diabetes mellitus and acromegaly. J Vet Intern Med 21: 892-898.

4. Blois SL, Holmberg DL (2008). Cryohypophysectomy used in the treatment of a case of feline acromegaly. J Small Anim Pract 49: 596-600.

5. Brearley MJ, Polton GA, Littler RM, Niessen SJ (2006). Coarse fractionated radiation therapy for pituitary tumours in cats: a retrospective study of 12 cases. Vet Comp Oncol 4: 209-217.

6. Chanson P, Salenave S, Kamenicky P, Cazabat L, Young J (2009). Pituitary tumours: acromegaly. Best Pract Res Clin Endocrinol Metab 23: 555-574.

7. Dunning MD, Lowrie CS, Bexfield NH, Dobson JM, Herrtage ME (2009). Exogenous insulin treatment after hypofractionated radiotherapy in cats with diabetes mellitus and acromegaly. J Vet Intern Med 23: 243-249.

8. Feldman EC, Nelson RW (2000). Acromegaly and hyperadrenocorticism in cats: a clinical perspective. J Feline Med Surg 2: 153-158.

9. Juul A (2003). Serum levels of insulin-like growth factor I and its binding proteins in health and disease. Growth Horm IGF Res 13: 113-170.

10. Kaser-Hotz B, Rohrer CR, Stankeova S, Wergin M, Fidel J, Reusch C (2002). Radiotherapy of pituitary tumours in five cats. J Small Anim Pract 43: 303-307.

11. Marek B, Kajdaniuk D, Kos KB, Ostrowska Z, Niedziol D, Janczewska-Kazek E (2001). Acromegaly and the risk of cancer. Pathophysiology 8: 69-75.

12. Meij BP, Auriemma E, Grinwis G, Buijtels JJ, Kooistra HS (2010). Successful treatment of acromegaly in a diabetic cat with transsphenoidal hypophysectomy. J Feline Med Surg 12: 406-410.

13. Meij BP, Vlugt-Meijer RH, Ingh TS, Rijnberk A (2004). Somatotroph and corticotroph pituitary adenoma (double adenoma) in a cat with diabetes mellitus and hyperadrenocorticism. J Comp Pathol 130: 209-215. 
14. Middleton DJ, Watson AD (1985). Glucose intolerance in cats given short-term therapies of prednisolone and megestrol acetate. Am J Vet Res 46: 2623-2625.

15. Niessen S, Scudder C, Forcada Y, Yallop E, Schmid H, Church DB (2013). Pasireotide (SOM230) opens doors to medical management of feline hypersomatotropism. J Vet Intern Med 685

16. Niessen SJ (2010). Feline acromegaly: an essential differential diagnosis for the difficult diabetic. J Feline Med Surg 12: 15-23.

17. Niessen SJ, Khalid M, Petrie G, Church DB (2007) Validation and application of a radioimmunoassay for ovine growth hormone in the diagnosis of acromegaly in cats. Vet Rec 160: 902-907.

18. Niessen SJ, Petrie G, Gaudiano F, Khalid M, Smyth JB, Mahoney P, Church DB (2007). Feline acromegaly: an underdiagnosed endocrinopathy? J Vet Intern Med 21: 899-905.

19. Norman EJ, Mooney CT (2000). Diagnosis and management of diabetes mellitus in five cats with somatotrophic abnormalities. J Feline Med Surg 2: 183-190.

20. Peterson ME (2007). Acromegaly in cats: are we only diagnosing the tip of the iceberg? J Vet Intern Med 21: 889-891.

21. Posch B, Dobson J, Herrtage M (2011). Magnetic resonance imaging findings in 15 acromegalic cats. Vet Radiol Ultrasound 52: 422-427.
22. Rijnberk A, Kooistra HS, Mol JA (2003). Endocrine diseases in dogs and cats: similarities and differences with endocrine diseases in humans. Growth Horm IGF Res 13A: 158-164.

23. Rosca M, Forcada Y, Solcan G, Church DB, Niessen SJ (2014). Screening diabetic cats for hypersomatotropism: performance of an enzyme-linked immunosorbent assay for insulin-like growth factor 1. J Feline Med Surg 16: 8288.

24. Scott-Moncrieff JC (2010). Insulin resistance in cats. Vet Clin North Am Small Anim Pract 40: 241-257.

25. Slingerland LI, Voorhout G, Rijnberk A, Kooistra HS (2008). Growth hormone excess and the effect of octreotide in cats with diabetes mellitus. Domest Anim Endocrinol 35: 352-361.

26. Starkey SR, Tan K, Church DB (2004). Investigation of serum IGF-I levels amongst diabetic and non-diabetic cats. J Feline Med Surg 6: 149-155.

27. Wallack ST, Wisner ER, Feldman EC (2003). Mensuration of the pituitary gland from magnetic resonance images in 17 cats. Vet Radiol Ultrasound 44: 278-282.

28. Zini E, Hafner M, Osto M, Franchini M, Ackermann M, Lutz TA, Reusch CE (2010). Predictors of clinical remission in cats with diabetes mellitus. J Vet Intern Med 24: 13141321. 